\title{
Aplicação de 1-metilciclopropeno e absorção de etileno em maçã da cultivar 'Royal Gala' colhida tardiamente
}

\author{
Application of 1-methylciclopropene and ethylene absorption on 'Royal Gala' apple late harvested
}

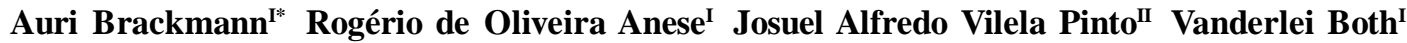 \\ Thiago Liberalesso Venturini ${ }^{\mathrm{I}}$ Márcio Renan Weber Schorr ${ }^{\mathrm{I}}$
}

\section{RESUMO}

\begin{abstract}
O objetivo deste trabalho foi avaliar a perda da eficiência do controle do etileno com o uso de 1-MCP e da sua absorção ao longo do período de oito meses de armazenamento em atmosfera controlada (AC) de maçãs da cultivar 'Royal Gala' colhidas em estádio de maturação avançado. Os frutos foram colhidos com firmeza da polpa de 89,5N; indice de iodo-amido de 6,7; acidez de 5,06meq $100 \mathrm{~mL}^{-1}$; teor de sólidos solúveis de 11,8 Brix; produção de etileno de $0,721 \mu \mathrm{L} \mathrm{C}_{2} \mathrm{H}_{4} \mathrm{~kg}^{-1} \mathrm{~h}^{-1}$; e respiração de $6,61 \mathrm{~mL} \mathrm{CO}_{2} \mathrm{~kg}^{-1} \mathrm{~h}^{-1}$. O delineamento experimental utilizado foi o inteiramente casualizado, com quatro tratamentos e seis repetições. Os frutos foram armazenados na temperatura de $0,5^{\circ} \mathrm{C}( \pm 0,1)$, sendo avaliadas as seguintes condições: [1] AC com $1,2 \mathrm{kPaO} \mathrm{O}_{2}+2,5 \mathrm{kPaCO}$; [2] AC com aplicação de $1 \mu L L^{-1}$ de 1-MCP; [3] AC com aplicação de $1 \mu L L^{-1}$ de $1-M C P$ e de $10 \mu L L^{-1}$ de etileno (AE); e [4] AC com baixa concentração de etileno $\left(<0,1 \mu L L^{-1}\right)(B E)$. O 1-MCP não apresentou eficiência na conservacão da firmeza da polpa em maçãs colhidas em estádio de maturação avançado, mas manteve eficiência na redução da atividade da enzima ACC oxidase, produção de etileno e atividade respiratória dos frutos.
\end{abstract}

Palavras-chave: Malus domestica, pós-colheita, armazenamento, qualidade.

\section{ABSTRACT}

The aim of this research was to evaluate the efficiency of the control of ethylene with 1-MCP application and its absorption in 'Royal Gala' apple fruit harvested at advanced maturity stages, during eight months of storage under controlled atmosphere (CA). The fruits were harvested with pulp firmness of $89.5 \mathrm{~N}$; iodine-starch index of 6.7; acidity of $5.06 \mathrm{meq} 100 \mathrm{~mL}^{-1}$; soluble solids content of $11.8^{\circ} \mathrm{Brix}$; ethylene

\begin{abstract}
production of $0.721 \mu \mathrm{L} \mathrm{C}_{2} \mathrm{H}_{4} \mathrm{~kg}^{-1} \mathrm{~h}^{-1}$ and respiration of $6.61 \mathrm{~mL}$ $\mathrm{CO}_{2} \mathrm{~kg}^{-1} \mathrm{~h}^{-1}$. The experimental design was completely randomized with four treatments and six replications. The fruits were stored at $0.5^{\circ} \mathrm{C}$, being evaluated at the following conditions: [1] $\mathrm{CA}$ with $1.2 \mathrm{kPa} \mathrm{O}_{2}+2.5 \mathrm{kPa} \mathrm{CO}_{2}$, [2] $\mathrm{CA}$ with application of $1 \mu \mathrm{L} \mathrm{L}^{-1}$ of 1-MCP, [3] CA with application of $1 \mu \mathrm{L} \mathrm{L}^{-1} 1-\mathrm{MCP}$ and $10 \mu \mathrm{L} L^{-1}$ of ethylene, and [4] CA with low ethylene concentration $\left(<0.1 \mu L L^{-1}\right)$. 1-MCP did not have effect on pulp firmness in apple fruit harvested at advanced maturity stage but reduced the activity of ACC oxidase, ethylene production and respiratory activity of the fruits.
\end{abstract}

Key words: Malus domestica, postharvest, storage, quality.

\section{INTRODUÇÃO}

A comercialização de maçãs de qualidade da cultivar 'Royal Gala' durante todo o ano é resultado de técnicas de armazenamento que envolvem o controle da temperatura e das concentrações de $\mathrm{O}_{2} \mathrm{e} \mathrm{CO}_{2}$, bem como do manejo do etileno, retardando o amadurecimento e a senescência dos frutos, por meio da redução da síntese de etileno $\left(\mathrm{C}_{2} \mathrm{H}_{4}\right)$ e da taxa respiratória, além da redução da incidência de distúrbios fisiológicos e podridões. O etileno é responsável por desencadear uma série de transformações bioquímicas que culminam no amadurecimento e na senescência dos frutos (LIEBERMAN 1979). Este se liga aos receptores presentes na membrana do retículo endoplasmático

'Departamento de Fitotecnia, Universidade Federal de Santa Maria (UFSM), Centro de Ciências Rurais (CCR). Av. Roraima, ${ }^{\circ}$ 1000, Cidade Universitária, Bairro Camobi, 97105-900, Santa Maria, RS, Brasil. E-mail: auribrackmann @ gmail.com. *Autor para correspondência.

IIUniversidade Federal da Fronteira Sul (UFFS), Campus de Laranjeiras do Sul, Laranjeira do Sul, PR, Brasil. 
(MA et al., 2006), transmitindo um sinal fisiológico para a síntese de enzimas que atuarão nos processos bioquímicos característicos do amadurecimento, como degradação da parede celular e quebra da clorofila (TAIZ \& ZEIGER, 2004). A aplicação pós-colheita de 1meticiclopropeno (1-MCP), inibidor da ação do etileno, pode manter a qualidade de frutos, como maçãs (BRACKMANN et al., 2004; 2005; CORRENT et al., 2004; 2005), peras (LELIÈVRE et al., 1997), bananas (SISLER \& SEREK, 1997) e abacates (KLUGE et al., 2002). O composto volátil 1-MCP, por possuir uma composição química semelhante ao etileno, liga-se irreversivelmente aos receptores de etileno de forma competitiva, no entanto não transmite o sinal característico desse fitohormônio e, deste modo, bloqueia sua ação na célula do fruto, retardando o amadurecimento (SISLER \& SEREK, 1997; BLANKENSHIP \& DOLE, 2003; WATKINS, 2006).

Entretanto, a eficiência do 1-MCP no bloqueio da ação do etileno e a consequente manutenção da qualidade da maçã da cultivar 'Royal Gala' durante o período de estocagem vêm sendo questionadas pelas empresas que armazenam maçãs e por pesquisadores. Trabalhando com maçãs da cultivar 'Royal Gala', CORRENT et al. (2004) e CORRENT et al. (2005) observaram redução da perda de firmeza e da produção de etileno e manutenção da acidez titulável com a aplicação do 1-MCP. No entanto, WATKINS et al. (2000) e MIR et al. (2001) não observaram efeito do 1-MCP sobre a conservação da acidez em diversas cultivares de maçãs. WATKINS et al. (2000) explicaram que esse comportamento se deve a variações de resposta dos frutos ao 1-MCP em função da cultivar, das condições edafoclimáticas e de cultivo, do ponto de colheita e das condições de armazenamento. Portanto, se a eficiência do 1-MCP está atrelada a diversos fatores, é necessário o conhecimento do efeito destes na conservação da fruta, já que a aplicação envolve elevados custos.

No Brasil, as empresas de maçãs geralmente apresentam grandes áreas com a cultivar 'Gala' e suas mutantes, o que dificulta a colheita de todos os frutos com maturação adequada para longos períodos de armazenamento. Em função disso, grande volume de fruto é colhido em estádio de maturação bastante avançado, ocorrendo maior demora no resfriamento dos frutos e na aplicação de 1-MCP na câmara. Esses fatores podem influenciar a eficiência do 1-MCP.

Diante do exposto, o objetivo deste trabalho foi avaliar a perda da eficiência do controle do etileno com o uso de 1-MCP e da sua absorção ao longo do período de oito meses de armazenamento em atmosfera controlada (AC) de maçãs da cultivar 'Royal Gala' colhidas em estádio de maturação avançado.

\section{MATERIAL E MÉTODOS}

Os frutos utilizados no experimento foram colhidos em pomar comercial localizado em Vacaria, Rio Grande do Sul (RS). O delineamento experimental utilizado foi o inteiramente casualizado, com seis repetições, sendo as unidades experimentais compostas por 20 frutos. Antes do armazenamento foi realizada uma seleção, sendo eliminados os frutos com lesões ou defeitos. Em seguida, as amostras experimentais foram homogeneizadas. Também foi realizada a análise inicial dos frutos, com três repetições compostas por 20 frutos.

Os frutos foram armazenados em minicâmaras experimentais de AC, com volume de $0,4 \mathrm{~m}^{3}$, e acondicionadas no interior de uma câmara frigorífica, com volume de $45 \mathrm{~m}^{3}$, e regulada na temperatura de $0,5^{\circ} \mathrm{C}$ $( \pm 0,1)$. Depois do fechamento das minicâmaras, foi realizada a instalação das atmosferas, por meio da injeção de $\mathrm{N}_{2}$, até a obtenção da pressão parcial de $\mathrm{O}_{2}$ preestabelecida. As pressões parciais de $\mathrm{CO}_{2}$ foram obtidas por meio da injeção desse gás nas minicâmaras até os níveis desejados. A temperatura da câmara foi regulada por meio de termostato eletrônico e acompanhada, diariamente, por meio de termômetros com bulbo de mercúrio inseridos na polpa de frutos. A umidade relativa permaneceu em torno de $96 \%( \pm 2,0)$ durante o período do experimento.

Os tratamentos avaliados foram: [1] AC com $1,2 \mathrm{kPaO}_{2}+2,5 \mathrm{kPa} \mathrm{CO}_{2} ;$ [2] AC com aplicação de $1 \mu \mathrm{LL}^{-1}$ de 1-MCP; [3] AC com aplicação de $1 \mu \mathrm{LL}^{-1}$ de 1-MCP e $10 \mu \mathrm{L} \mathrm{L}^{-1}$ de etileno (AE) durante todo período de armazenamento; e [4] AC com baixa concentração de etileno $\left(<0,1 \mu \mathrm{L} \mathrm{L}^{-1}\right)$ (BE) durante todo o período de armazenamento. Para a manutenção constante dos níveis de $\mathrm{O}_{2}$ e $\mathrm{CO}_{2}$, estes foram monitorados e corrigidos diariamente. $\mathrm{O}$ monitoramento foi feito com um sistema de controle automático de gases da marca Kronenberger-Climasul. $\mathrm{O} \mathrm{O}_{2}$ consumido pela respiração foi reposto por meio da injeção de ar nas minicâmaras. $\mathrm{O} \mathrm{CO}_{2}$ em excesso foi absorvido por uma solução de hidróxido de potássio (40\%), por meio da qual foram circulados os gases das minicâmaras.

$\mathrm{O}$ etileno foi absorvido do interior da minicâmara com o uso de saches contendo permanganato de potássio $\left(\mathrm{KMnO}_{4}\right)$, utilizando-se o produto comercial Always Fresh na proporção de 50g do produto por quilograma de fruto. O etileno do interior das minicâmaras com $10 \mu \mathrm{L} \mathrm{L}^{-1} \mathrm{e}$ a absorção de etileno foram monitorados semanalmente por meio da determinação por cromatografia gasosa. Para os tratamentos com 1-MCP, este foi aplicado em uma minicâmara experimental, hermeticamente fechada, 
durante 24 horas, na temperatura de armazenamento, utilizando-se o produto Smart Fresh ${ }^{\circledR}(0,14 \%)$ como fonte de 1-MCP. O produto foi solubilizado em $25 \mathrm{~mL}$ de água, a $25^{\circ} \mathrm{C}$, em um recipiente hermético, e posteriormente a solução foi transferida para uma placa de petri no interior da minicâmara, que foi imediatamente fechada. Os frutos ficaram expostos ao tratamento por 24 horas e, em seguida, a minicâmara foi ventilada, com o auxílio de uma bomba de ar. Para o tratamento com alto etileno, este, no momento da instalação do experimento, recebeu a aplicação de $10 \mu \mathrm{L} \mathrm{L}^{-1}$ de etileno, sendo monitorado e corrigido semanalmente.

As análises laboratoriais foram realizadas aos zero, quatro, seis, sete e oito meses de armazenamento. Os frutos foram retirados das minicâmaras, e cada amostra foi dividida em duas subamostras, uma para análise na saída da câmara e outra para análise aos sete dias de exposição a $20^{\circ} \mathrm{C}$, simulando o período de comercialização. As variáveis analisadas foram: ocorrência de podridões e degenerescência, obtidas pela porcentagem de frutos que apresentavam sinais característicos; coloração da epiderme, determinada com um colorímetro, marca Minolta, pelo sistema tridimensional de cores CIE LC $\mathrm{H}$; acidez titulável, pela titulação de $10 \mathrm{~mL}$ de suco em $100 \mathrm{~mL}$ de água destilada, com solução de $\mathrm{NaOH} 0,1 \mathrm{~N}$, até $\mathrm{pH} 8,1$; teor de sólidos solúveis (SS), determinado com auxílio de um refratômetro manual com correção de temperatura; firmeza de polpa, determinada com o uso de um penetrômetro com ponteira de $11 \mathrm{~mm}$ de diâmetro; produção de etileno, com utilização de um cromatógrafo a gás, equipado com coluna Poropak $\mathrm{Ne}$ detector de ionização de chama, com uma temperatura da coluna, do injetor e do detector de 90,140 e $200^{\circ} \mathrm{C}$, respectivamente; respiração, obtida por meio da produção de $\mathrm{CO}_{2}$, com auxílio de um analisador de fluxo contínuo de gás, marca Agri-Datalog; e atividade da ACC oxidase (Ácido 1-aminociclopropano-1carboxílico oxidase), de acordo com a metodologia proposta por BUFLER (1986).

Os dados obtidos para cada variável avaliada foram submetidos à análise de variância, sendo as médias comparadas pelo teste de Tukey, a 5\% de probabilidade de erro. As variáveis expressas em porcentagem foram transformadas em $\operatorname{arc} . \operatorname{sen} \sqrt{\mathrm{x} / 100}$, antes da análise de variância.

\section{RESULTADOS E DISCUSSÃO}

Os frutos apresentavam, no momento da colheita, índice iodo-amido de 6,70; firmeza de polpa de $89,5 \mathrm{~N}$; acidez de 5,06 meq $100 \mathrm{~mL}^{-1}$; teor de sólidos solúveis de $11,8^{\circ}$ Brix; produção de etileno de $0,721 \mu \mathrm{L}$
$\mathrm{C}_{2} \mathrm{H}_{4} \mathrm{~kg}^{-1} \mathrm{~h}^{-1}$ e respiração de $6,61 \mathrm{~mL} \mathrm{CO}_{2} \mathrm{~kg}^{-1} \mathrm{~h}^{-1}$. Para as variáveis ocorrência de podridões, acidez titulável, coloração e degenerescência de polpa, não houve diferença estatística significativa.

Quanto ao teor de SS, este também foi pouco influenciado pelos tratamentos (Figura 1), resultado encontrado por outros autores, como WATKINS et al. (2000), MIR et al. (2001) e CURRENT et al. (2005). Somente aos quatro meses de armazenamento, na análise aos sete dias de exposição a $20^{\circ} \mathrm{C}$, o teor de SS foi menor nos frutos submetidos à absorção de etileno. Nos demais tempos de avaliação, não houve diferença estatística do teor de SS para os tratamentos avaliados.

Para a firmeza da polpa, os frutos tratados com 1-MCP não apresentaram diferença estatística daqueles que foram submetidos à absorção de etileno, em todas as avaliações (Figura 1). Se comparado com a testemunha, o 1-MCP apresentou eficiência superior à AC somente na avaliação realizada na saída da câmara aos sete meses. $\mathrm{O}$ tratamento com absorção de etileno também apresentou diferença estatística da testemunha somente em uma análise, após seis meses de armazenamento e sete dias de exposição a $20^{\circ} \mathrm{C}$. Essa perda da firmeza da polpa é resultante de alterações nas características dos polissacarídeos da lamela média da parede celular (BATISSE et al., 1994), devido à ação do etileno (SISLER \& SEREK, 1997), evidenciando a falta de eficiência do 1-MCP e da absorção de etileno. Esses resultados contrariam um grande número de trabalhos (FAN et al., 1999; CORRENT et al., 2004; 2005; BRACKMANN et al., 2004; 2005); no entanto, deve-se considerar que essa ineficiência do manejo do etileno pode ser devido à avançada maturação, que é confirmada por WATKINS et al. (2000). Deve-se atentar para o fato de que, na colheita, os frutos apresentavam firmeza da polpa elevada $(89,5 \mathrm{~N})$; entretanto, o índice iodo-amido também estava alto $(6,7)$, o que demonstra a acentuada degradação do amido nos frutos, induzido pelo etileno, cuja produção era de $0,721 \mu \mathrm{L} \mathrm{kg}^{-1} \mathrm{~h}^{-1}$. Provavelmente o índice iodo-amido é uma variável que identifica o estádio de maturação da maçã de forma mais eficiente que a variável firmeza da polpa. Portanto, a eficiência do 1-MCP ou absorção de etileno, provavelmente, somente sejam eficientes em índices de iodo-amido mais baixo, mesmo que a firmeza ainda esteja alta.

A produção de etileno foi menor nos frutos tratados com 1-MCP na maioria das avaliações, mantendo-se menor que $0,20 \mu \mathrm{LC}_{2} \mathrm{H}_{4} \mathrm{~kg}^{-1} \mathrm{~h}^{-1}$, no entanto não apresentando diferença estatística em algumas das avaliações (Figura 2). Esse fato deve estar associado à menor atividade da enzima ACC oxidase (Figura 1), já que esta é responsável pela oxidação da molécula de 


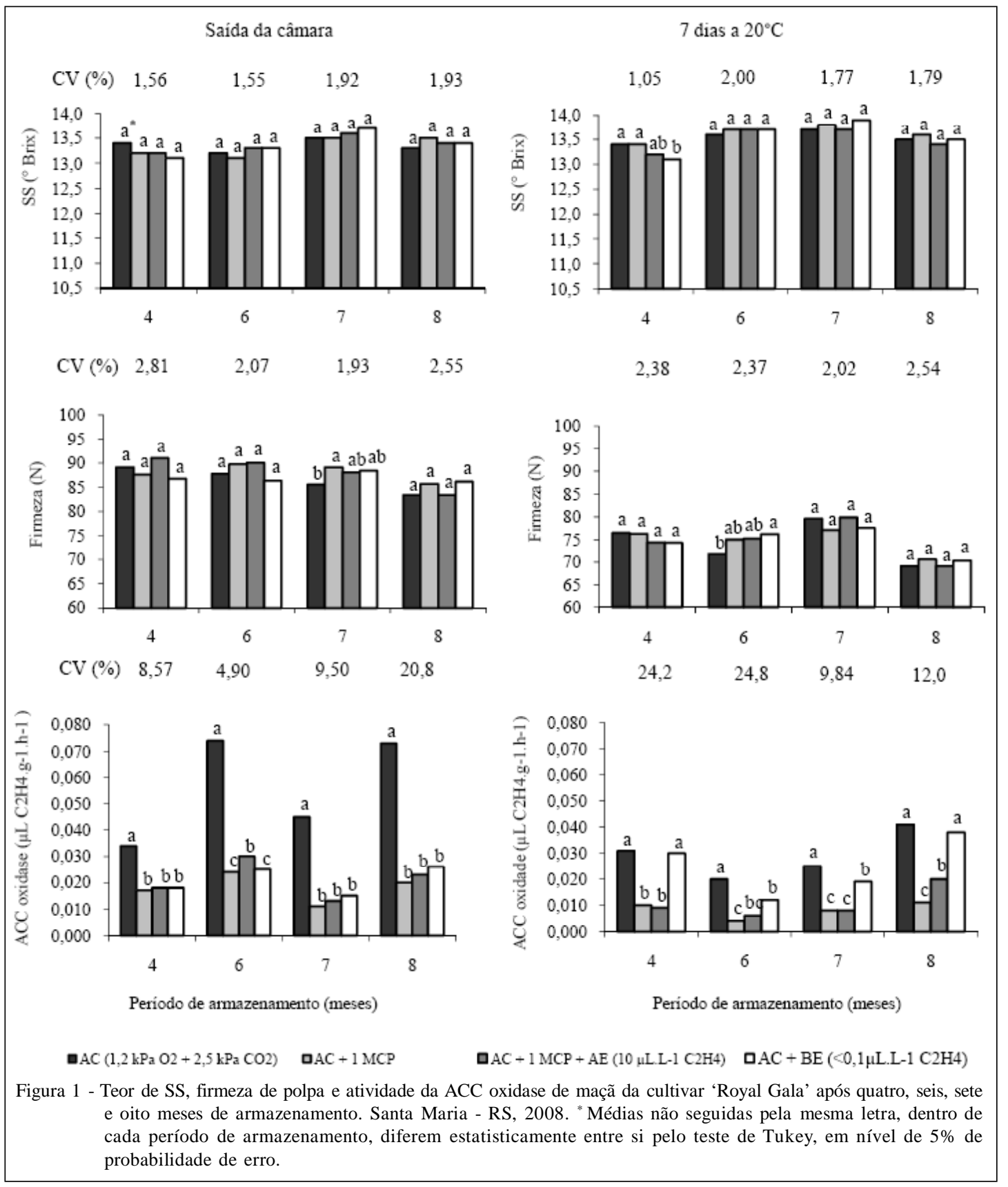

ACC a etileno (LEIBERMAN, 1979; YANG \& HOFFMAN, 1984; KENDE, 1993). O tratamento que recebeu a aplicação de 1-MCP mais $10 \mu \mathrm{L} \mathrm{L}^{-1}$ de etileno, aos seis e sete meses de armazenamento, manteve baixo nível de produção de etileno até os três e quatro dias, a $20^{\circ} \mathrm{C}$, respectivamente. Possivelmente, isso seja em função de o 1-MCP estar atuando de forma mais eficiente após o armazenamento em AC. Aos seis meses, também o 1-MCP inibiu a síntese de etileno depois de três dias a $20^{\circ} \mathrm{C}$, e maçãs em baixo etileno retardaram a capacidade de produzir etileno a essa temperatura. Já aos oito meses, o tratamento 1-MCP mais $10 \mu \mathrm{L} \mathrm{L}^{-1} \mathrm{de}$ etileno apresentou maior produção de etileno no início do período de exposição a $20^{\circ} \mathrm{C}$. Esses resultados sugerem que o 1-MCP perdeu, ao longo do tempo de armazenamento, a capacidade de inibir a ação do etileno, por isso, na presença de $10 \mu \mathrm{L} \mathrm{L}^{-1}$ de etileno durante o armazenamento, este estimulou a sua síntese em $20^{\circ} \mathrm{C}$. A causa da ineficiência provavelmente seja devido aos receptores não estarem mais sendo inibidos pelo 1- 


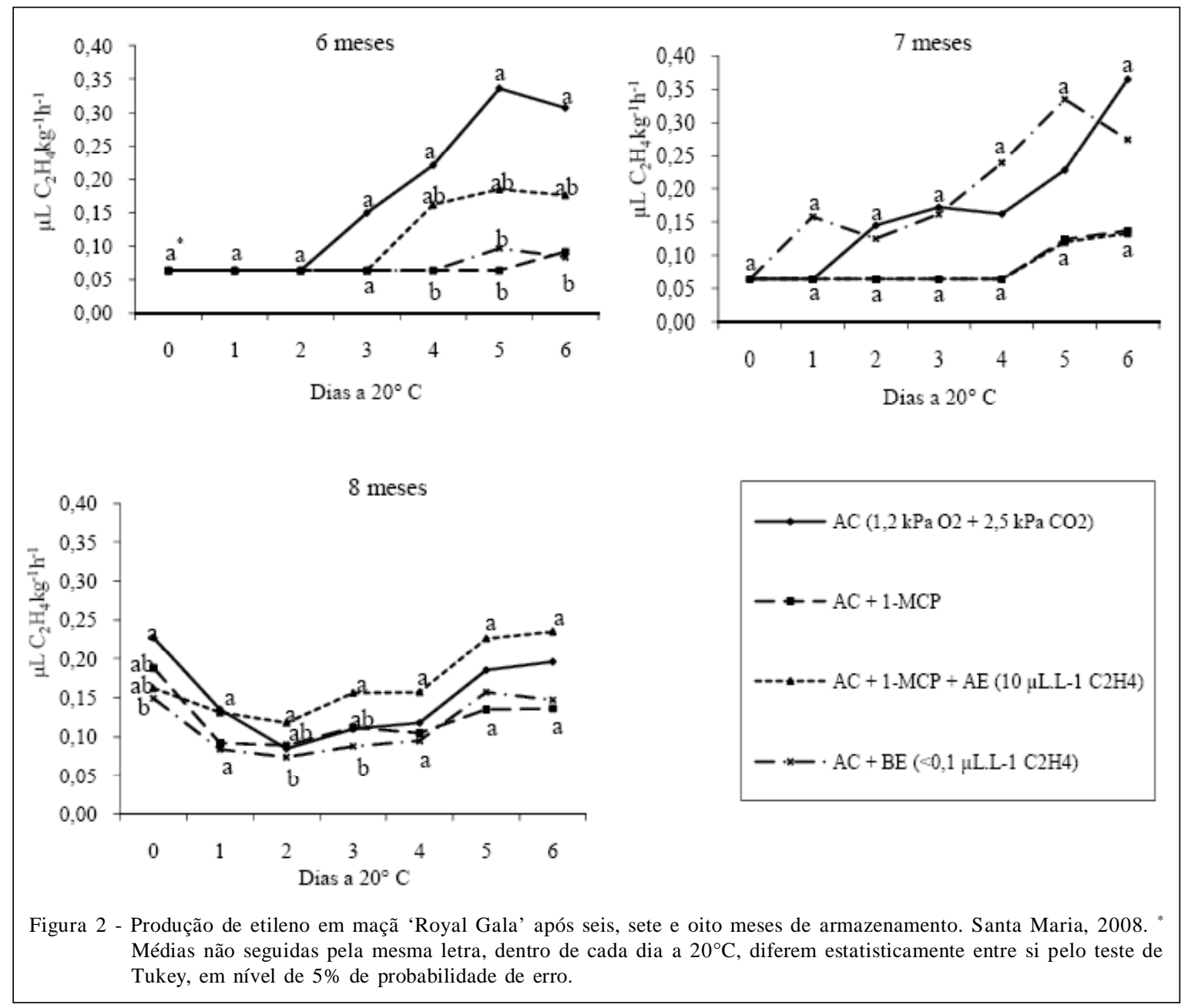

MCP, o que poderia ser decorrente da síntese de novos receptores de etileno durante o armazenamento, o que aumenta a síntese autocatalítica de etileno (LELIĖVRE et al., 1997) e a sensibilidade a esse fitohormônio.

Semelhante ao que ocorreu com a produção de etileno, a respiração dos frutos tratados com 1-MCP foi menor na maioria das avaliações (Figura 3). Resultados semelhante foram reportados por BRACKMANN et al. (2004) e BRACKMANN et al. (2005). O tratamento com 1-MCP mais exposição a $10 \mu \mathrm{L}$ $\mathrm{L}^{-1}$ de etileno apresentou elevada respiração aos oito meses, nos primeiros dias de avaliação, o que não foi verificado aos seis e sete meses, evidenciando de novo a perda de eficiência do 1-MCP. Com maior atividade respiratória, ocorre maior consumo de reservas do tecido do fruto, como, por exemplo, açúcares e ácidos orgânicos, o que resulta em perda de qualidade do mesmo. Tendo em vista que a maior respiração está associada à maior produção de etileno, pode haver também redução da firmeza da polpa e diminuição da coloração verde dos frutos devido ao fato de o etileno ativar enzimas que degradam a parede celular e quebrar clorofilas.

Aatividade da enzima ACC oxidase foi maior na testemunha em todos os períodos de avaliação (Figura 1), concordando com a maior produção de etileno observada nessa condição em algumas avaliações (Figura 2). Nos tratamentos com bloqueio da ação do etileno, a atividade da ACC oxidase mantevese baixa em todos os períodos de avaliação, confirmando resultados encontrados por BRACKMANN et al. (2008). Frutos com absorção de etileno também apresentaram baixa atividade da ACC oxidase, porém somente na saída da câmara. Provavelmente, o baixo $\mathrm{CO}_{2}$ e o alto $\mathrm{O}_{2}$ durante a exposição dos frutos a $20^{\circ} \mathrm{C}$ tenham estimulado a atividade da enzima e a síntese de etileno. Durante a vida útil dos frutos, a enzima foi ativada pelo $\mathrm{O}_{2}$, pelo $\mathrm{CO}_{2}$ e pela temperatura; entretanto, os frutos tratados com 1-MCP continuaram a apresentar inibição da atividade dessa enzima a $20^{\circ} \mathrm{C}$. 


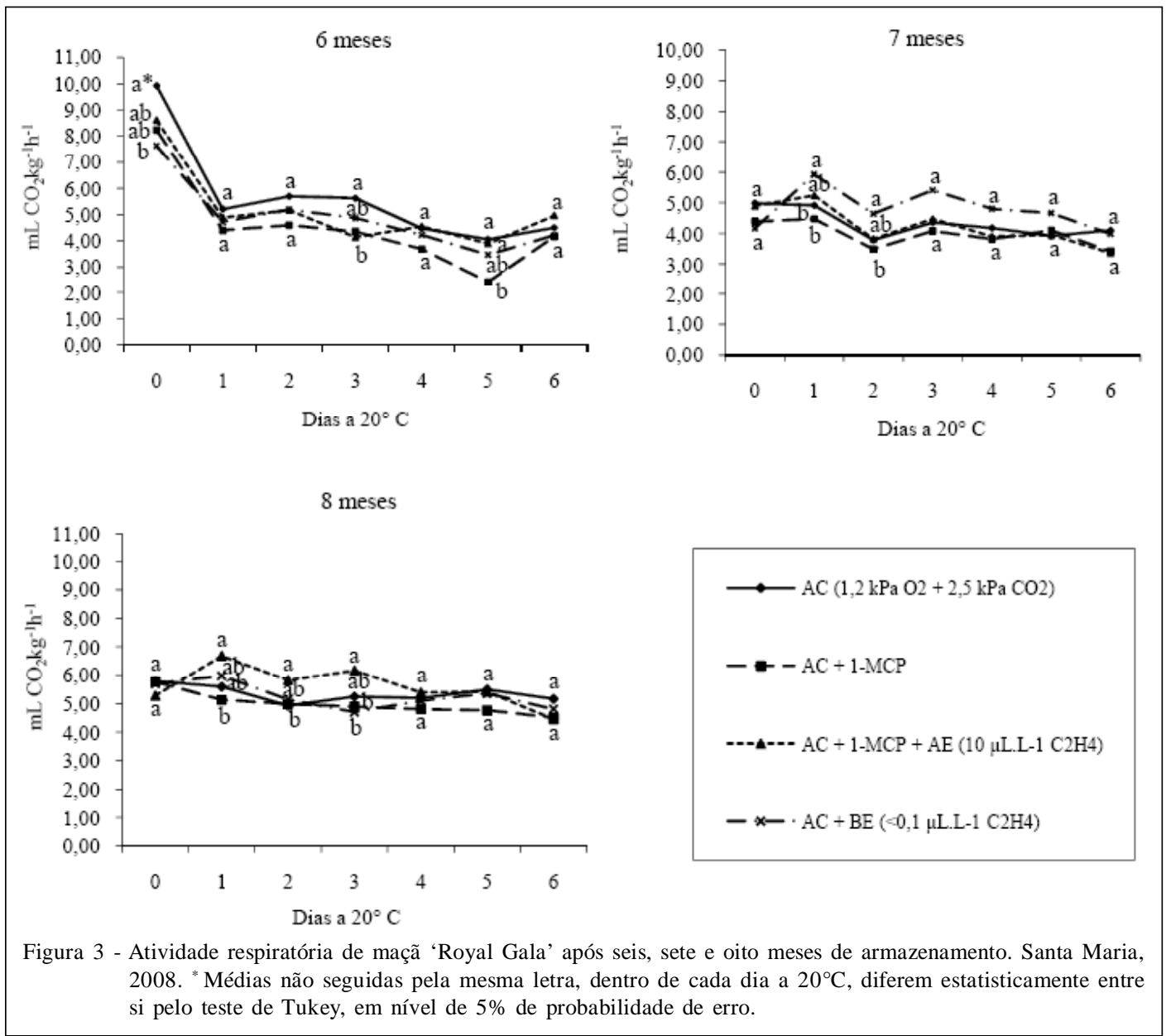

\section{CONCLUSÃO}

O 1-MCP reduziu a atividade da enzima ACC oxidase, a síntese de etileno e a respiração até o oitavo mês de armazenamento, mas esse efeito não influenciou a perda da firmeza em todo o período de armazenamento das maçãs da cultivar 'Royal Gala' colhidas em estádio avançado de maturação. A absorção de etileno também não foi eficiente para atrasar o avanço da maturação em maçãs colhidas tardiamente.

\section{REFERÊNCIAS}

MA, B. et al. Subcellular localization and membrane topology of the melon ethylene receptor CmERS1. Plant Physiology, v.141, p.587-597, 2006. Disponível em: <http:// www.plantphysiol.org/cgi/reprint/141/2/587>. Acesso em: 24 set. 2009. doi:10.1104/pp.106.080523.

BATISSE, C. et al. Pectin changes in ripening cherry fruit. Journal of Food Science, v.59, n.2, p.389-393, 1994. Disponível em: <http://onlinelibrary.wiley.com/doi/10.1111/ j.1365-2621.1994.tb06974.x/abstract>. Acesso em: 14 ago. 2009. doi: 10.1111/j.1365-2621.1994.tb06974.x.

BLANKENSHIP, S.M.; DOLE, J.M. 1-Methylcyclopropene: a review. Postharvest Biology and Technology, v.28, p.1-25, 2003. Disponível em: <http://www.sciencedirect.com/ science?_ob=ArticleURL\&_udi=B 6TBJ-47WD9G3 $3 \&$ \& user $=687358 \&$ \&coverDate $=04 \% 2$ F $30 \% 2$ F 2003 \&_rdoc=1\&_fmt=high\&_orig=search\&_sort=d\&_docanchor $=\& v i e w=\mathrm{c}$ \&_searchStrId=1436752816\&_rerunOrigin $=$ g oogle\&_acct $=$ C000037899\&_version $=1 \&$ _urlVersion $=0$ \&_userid $=687358 \mathrm{\& md} 5=6473168 \mathrm{~b} 6 \mathrm{e} 0 \mathrm{a} 317691 \mathrm{c} 41 \mathrm{a} 7 \mathrm{a} 1 \mathrm{fa} 7314 \mathrm{a}>$. Acesso em: 13 jul. 2009. doi: 10.1016/S0925-5214(02)00246-6.

BRACKMANN, A. et al. O resfriamento rápido e a rápida instalação da atmosfera controlada como substitutos do 1-MCP no armazenamento de maçã 'Gala'. Revista Brasileia de Fruticultura, v.27, n.3, p.379-382, 2005. Disponível em: <http://www.scielo.br/pdf/rbf/v27n3/27778.pdf>. Acesso em: 02 maio, 2009. doi: 10.1590/S0100-29452005000300010.

BRACKMANN, A. et al. Qualidade da maçã cv. Gala tratada com 1-metilciclopropeno. Ciência Rural, v.24, n.5, p.14151420, 2004. Disponível em: <http://www.scielo.br/pdf/cr/ v34n5/a14v34n5.pdf>. Acesso em: 16 jun. 2009. doi: 10.1590/ S0103-84782004000500014. 
BRACKMANN, A. et al. Qualidade da maçã 'Gala' armazenada em atmosfera controlada associada à absorção e ao controle da síntese e da ação do etileno. Ciência Rural, v.38, n.8, p.21512156, 2008. Disponível em: <http://www.scielo.br/ s cie lo.ph p s c ri pt $=$ sci_art text \& pid=S 0103 84782008000800010>. Acesso em: 16 jun. 2009. doi: 10.1590/ S0103-84782008000800010.

BUFLER, G. Ethylene-promoted conversion of 1aminocyclopropene-1-carboxylic acid to ethylene in peel of apple at various stages of fruit development. Plant Physiology, v.80, p. 539-543, 1986. Disponível em: <http:/ /www.plantphysiol.org/cgi/reprint/80/2/539.pdf>. Acesso em: 19 ago. 2010. doi: 0032-0889/86/80/0539/05/\$01.00/0.

CORRENT, A.R. et al. Uso do 1-metilciclopropeno no controle da maturação de maçãs cv. Royal Gala. Revista Brasileira de Fruticultura, v.27, n.2, p.207-210, 2005. Disponível em: <http://www.scielo.br/pdf/rbf/v27n2/a06v27n2.pdf>. Acesso em: 13 ago. 2009. doi: 10.1590/S0100-29452005000200006.

CORRENT, A.R. et al. Efeito do 1-metilciclopropeno na conservação de maçãs 'Royal Gala' em ar refrigerado e atmosfera controlada. Revista Brasileira de Fruticultura, v.26, n.2, p.217-221, 2004. Disponível em: <http://www.scielo.br/pdf/ rbf/v26n2/21810.pdf>. Acesso em: 13 ago. 2009. doi: 10.1590/ S0100-29452004000200009.

FAN, X. et al. 1-Methylcyclopropene inhibits apple ripening. Journal American Society for Horticultural Science, v.24, p.690-695, 1999.

KENDE H. Ethylene biosynthesis. Annual Review Plant Physiology and Plant Molecular Biology, n.44, p.283-307, 1993. Disponível em: <http://arjournals.annualreviews.org/doi/pdf/ 10.1146/annurev.pp.44.060193.001435?cookieSet=1>. Acesso em: 20 ago. 2010. doi:10.1146/annurev.pp.44.060193.001435.

KLUGE, R.A. et al. Inibição do amadurecimento de abacate com 1-Metilciclopropeno. Pesquisa Agropecuária Brasileira, v.37, n.7, p.895-901, 2002. Disponível em: <http:/ /www.scielo.br/pdf/pab/v37n7/10791.pdf>. Acesso em: 28 set. 2009. doi: 10.1590/S0100-204X2002000700001.

LELIÈVRE, J.M. et al. Effects of chilling on the expression of ethylene biosynthetic genes in Passes-Crassane pear (Pyrus communis L) fruits. Plant Molecular Biology, v.23, p.847855, 1997. Disponível em: <http://oatao.univ-toulouse.fr/1809/ 1/Leli\%C3\%A8vre_1809.pdf>. Acesso em: 14 set. 2009. doi: 10.1023/A: 1005750324531 .

LIEBERMAN, M. Biosynthesis and action of ethylene. Annual Review of Plant Physiology, v.30, p.533-591, 1979. Disponível em: <http://arjournals.annualreviews.org/doi/pdf/ 10.1146/annurev.pp.30.060179.002533>. Acesso em: 15 out. 2009. doi:10.1146/annurev.pp.30.060179.002533.

MIR, A.N. et al. Harvest maturity, storage temperature, and 1MCP application frequency alter firmness retention and chlorophyll fluorescence of 'Redchief Delicious' apples. Journal of the American Society for Horticultural Science, v.126, n.5, p.618-624, 2001. Disponível em: <http:/ /www.phtnet.org/research/download/pdf/wz372.pdf>. Acesso em: 12 nov. 2009.

SISLER, E.C.; SEREK, M. Inhibitors of ethylene responses in plants at the receptor level: recent developments. Physiologia Plantarum, v.100, p.577-582, 1997. Disponível em: <http:/ /onlinelibrary.wiley.com/doi/10.1111/j.13993054.1997.tb03063.x/pdf>. Acesso em: 21 jul. 2009. doi: 10.1111/j.1399-3054.1997.tb03063.x.

TAIZ, L.; ZEIGER, E. Fisiologia vegetal. Trad. Eliane Romanato Santarém ... (et al.). 3.ed. Porto Alegre. Artmed, 2004. 719p.

WATKINS, C.B. The use of 1-Methylcyclopropene (1-MCP) on fruits and vegetables. Postharvest Biology and Technology, v.24, p.389-409, 2006. Disponível em: <http:// www.sciencedirect.com/science?_ob=ArticleURL\&_udi=B6T4X4JFGFB 4-1\&_user $=687358 \&$ _coverDate $=08 \% 2$ F3 $1 \% 2$ F20 $06 \&$ \&doc $=1 \&$ \&mt $=$ high $\&$ _orig $=$ search \&_sort $=d \&$ d ocanchor $=\&$ view $=$ c \&_searchStrId $=1436990571 \&$ _rerunOrigin $=$ google\&_acct $=$ C000037899\&_version $=1 \&$ \&urlVersion $=0$ \&_userid $=687358 \& \mathrm{md} 5=\mathrm{fe} 39 \mathrm{~cd} 52 \mathrm{c} 604 \mathrm{~b} 244 \mathrm{a} 5 \mathrm{e} 3460 \mathrm{e} 9 \mathrm{e} 82 \mathrm{e} 02 \mathrm{e}>$. Acesso em: 14 out. 2009. doi: 10.1016/j.biotechadv.2006.01.005.

WATKINS, C.B. et al. Responses of early, mid and late season apple cultivars to postharvest application of 1methylcyclopropene (1-MCP) under air and controlled atmosphere storage conditions. Postharvest Biology and Technology, v.19, p.17-32, 2000. Disponível em: <http:// w $\mathrm{w}$ w. $\mathrm{s}$ c $\mathrm{i}$ e $\mathrm{n}$ c e $\mathrm{d}$ i $\mathrm{r}$ e $\mathrm{c}$ t. science?_ob=ArticleURL\&_udi=B6TBJ-405TFWP$3 \&$ \& user $=687358 \&$ _coverDat e $=05 \% 2$ F $31 \% 2$ F 2 $000 \&$ \&doc $=1 \&$ \&mt $=$ high $\&$ _orig $=$ search $\&$ _sort $=$ d \&_doc anchor $=\&$ view $=c \&$ \&_searchStrId $=1436992520 \&$ rerun Origin $=$ google $\&$ _acct $=\mathrm{C} 000037899 \&$ _version $=1 \&$ \&url Version $=0 \&$ userid=687358\&md5=77a4e2d56blbf5749532bd9c588e0b03 > Acesso em: 14 out. 2009. doi: 10.1016/S09255214(00)00070-3.

YANG, S.F.; HOFFMAN, N.E. Ethylene biosynthesis and its regulation in higher plants. Annual Review of Plant Physiology, v.35, p.155-189, 1984. Disponível em: <http:// arjournals.annualreviews.org/doi/pdf/10.1146/ annurev.pp.35.060184.001103>. Acesso em: 13 maio, 2009. doi:10.1146/annurev.pp.35.060184.001103. 